\title{
Seasonal variability of sea surface chlorophyll-a of waters around Sri Lanka
}

\author{
KANTHI K A S YAPA \\ Department of Physics, University of Ruhuna, Matara, Sri Lanka.
}

\begin{abstract}
Remotely sensed data on ocean colour of waters surrounding Sri Lanka received from the Coastal Zone Colour Scanner (CZCS) are processed and analyzed. Raw data of $1 \mathrm{~km}$ resolution on relatively cloud free days during 1978-1986 are processed to produce sea surface chlorophyll maps within latitudes $4.5 \mathrm{~N}-11 \mathrm{~N}$ and longitudes 78E-85E, a region in the Indian Ocean surrounding Sri Lanka. The processed data include about 110 single day maps and composite averages for each month and season. The months of July, August and September are omitted in the calculation of averages due to insufficient data. The waters in the Gulf of Mannar and Palk Bay areas show high chlorophyll-a concentrations throughout the year. However, these high values may represent other suspended particles and dissolved organic matter besides chlorophyll-a as this region is shallow $(<100 \mathrm{~m})$. Regions with high chlorophyll concentrations $(>0.5 \mathrm{mg}$ $\mathrm{m}^{-3}$ ) along the coast and western ocean region can be seen in the months of October and November, after the southwest monsoon period. As high surface chlorophyll concentrations may indicate high productivity, these regions need extensive measurements of primary production and also continuous monitoring of fish catches, during and after the southwest monsoon. Studies of particle composition in shallow water areas, in particular waters in Palk Bay and Gulf of Mannar, should be carried out in order to elucidate the effect of non-phytogenic.
\end{abstract}

\section{Introduction}

Ocean colour is affected by marine plants, suspended sediments and dissolved organic matter, particularly near the coast. The pigment chlorophyll-a, found in microscopic plant phytoplankton, is known to produce systematic variations in the colour of the ocean. In open ocean waters, ocean colour is used as an indicator of chlorophyll-a concentration. Coastal Zone Colour Scanner (CZCS), designed to monitor ocean colour, was operational from 1978 until 1986 and an impressive archive of data is available for analysis and oceanographic interpretation. Data from CZCS have been used in studies of many regions of world oceans, extensively in North Atlantic and in the Arabian Sea. However, waters around Sri Lanka have not been given much attention, mainly due to the fact that oceanography is not a well-established field of research in Sri Lanka. Here, the variability of surface phytoplankton pigments in Indian Ocean waters around Sri Lanka has been studied using CZCS raw data. The knowledge of surface pigment concentrations can be used in the location upwelling areas off the coast. When upwelling brings nutrients to sunlit waters primary production increases, thus attracting fishes to graze the new production. Fishes belong to the family of clupeidae such as sprats, herrings and sardines have commercial importance in Sri Lanka. Also, exploitation of large pelagic fishes such as tunas, tuna-like fishes, king mackerels, etc. around Sri Lanka is presently linked to the area within and up to a little beyond the edge of the continental shelf. Therefore, this knowledge will be highly beneficial in identifying possible fishing grounds off the coast of Sri Lanka for the development of the fisheries industry in the country.

\section{Materials and Methods}

An ocean colour sensor records upward radiance from the sea surface after modification by the intervening

Keywords. Chlorophyll-a; CZCS; Sri Lanka; seasonal variability; fishery industry. 
atmospheric path. The significance of the emergent flux from the sea is that it contains information about the optical properties of the ocean and thus about the concentrations of the optically significant constituents in the water. Empirical relationships have been established (Sathyendranath and Morel 1983; Gordon et al 1975; Morel and Prieur 1977) to link changes in radiance (corrected for atmospheric effects) with changes in concentration of chlorophyll-a. An algorithm, which has the form $C=A\left[L\left(\lambda_{1}\right) / L\left(\lambda_{2}\right)\right]^{\mathrm{B}}$, is most commonly used to estimate chlorophyll-a concentration $\left(\mathrm{C}\right.$ in $\left.\mathrm{mg} \mathrm{m}^{-3}\right)$ of surface waters. Here, $L$ is the radiance (watts $\mathrm{m}^{-2}$ steradian $^{-1}$ ), $\lambda_{1}$ and $\lambda_{2}$ are wavelengths and, $A\left(\mathrm{mg} \mathrm{m}^{-3}\right)$ and $B$ (dimensionless) are empirically determined coefficients. In the case of CZCS, the wavelengths used are 443 and $550 \mathrm{~nm}$ for low pigment concentrations and 520 and $550 \mathrm{~nm}$ for high pigment concentrations. Here, we have used an algorithm (SEAPAK) developed at NASA which uses coefficients $A=1.13$ and $B=-1.71$ (after Gordon and Morel 1983) for retrieval at low chlorophyll-a concentrations $(C \leq 1.5)$ and coefficients $A=3.326$ and $B=-2.439$ for retrieval at high chlorophyll-a concentrations $(C>1.5)$. The algorithm has been found to be most effective in open ocean or case 1 waters (Sathyendranath and Morel 1983; Gordon and Morel 1983) where phytoplankton and their deriva- tive products play the dominant role in determining the optical properties of the ocean. In coastal and shallow waters (classified as case 2 waters where inorganic and/or organic sediments make an important or dominant contribution to the optical properties) retrieval of pigment concentration is more complex and less reliable due to inherent limitations in the CZCS channels and in the algorithm. Therefore, the derived values will be discussed only qualitatively in such areas.

We have processed LAC (Local Area Coverage) data of about $1 \mathrm{~km}$ resolution, obtained through NASA's Goddard Distributed Active Archive to produce sea surface chlorophyll-a maps of waters surrounding Sri Lanka. Raw data at local noon on relatively cloud free days during 1978-1986 were processed to produce chlorophyll maps of waters in latitudes between $4.5 \mathrm{~N}$ and $11 \mathrm{~N}$ and longitudes between $78 \mathrm{E}$ and $85 \mathrm{E}$. The bottom topography of the ocean around Sri Lanka within the study area is shown in figure 1 . The territorial waters of Sri Lanka are within 12 nautical miles measured from the baselines while the Economic Exclusive Zone (EEZ) extends to a distance of 200 nautical miles from the baselines (the southwest farthest point boundary is $4^{\circ} 47.04^{\prime} \mathrm{N}$ and $77^{\circ} 01.40^{\prime} \mathrm{E}$ and the northeast boundary is $11^{\circ} 26.6^{\prime} \mathrm{N}$ and $83^{\circ} 22^{\prime} \mathrm{E}$ ). There were some periods of

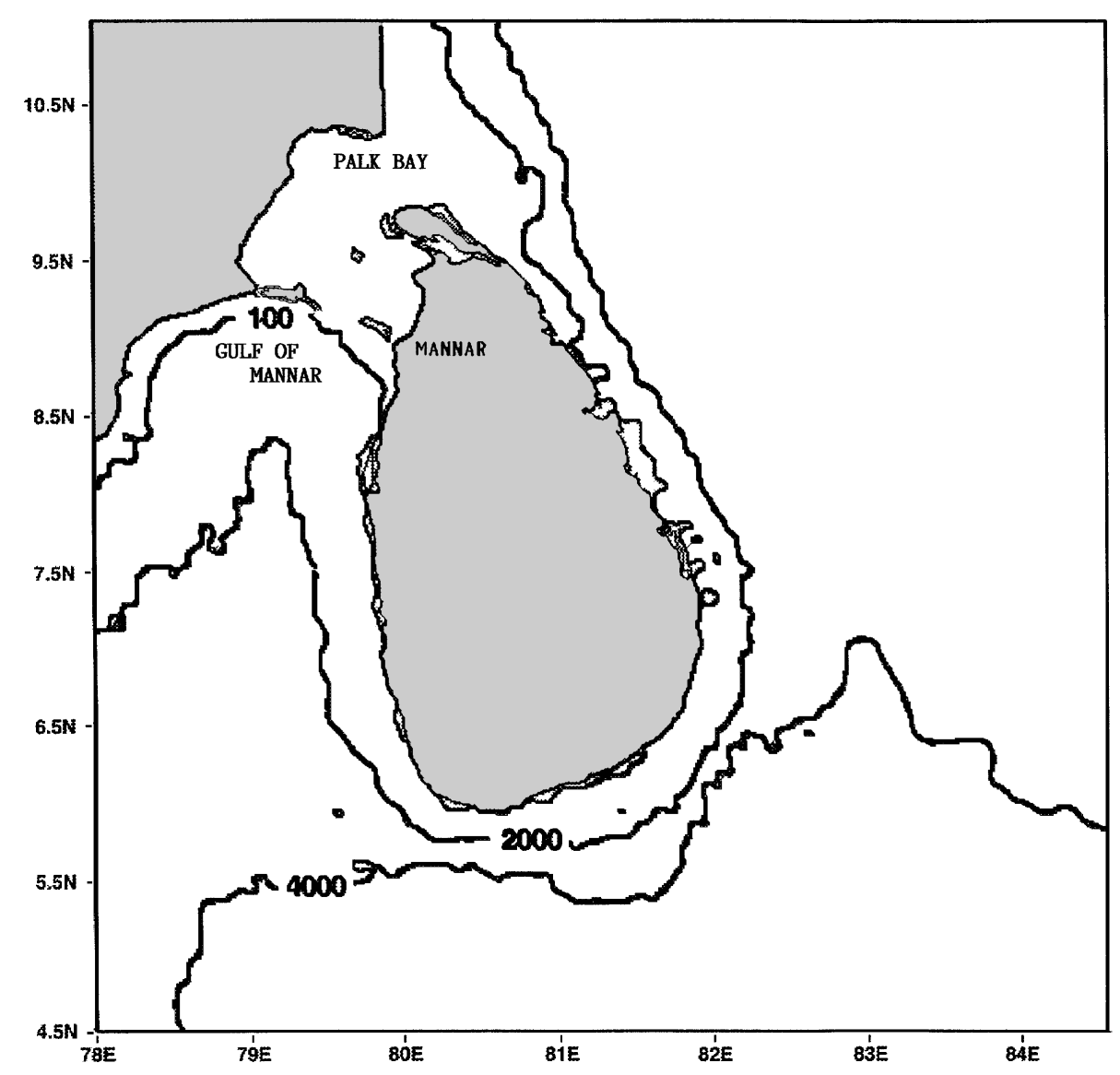

Figure 1. Bottom topography of the ocean around Sri Lanka (depths are given in meters). 
missing data due to shutting off of the sensor due to technical and other reasons (lack of continuous archiving of LAC data may have also been due to very little or no interest shown by ocean scientists from this part of the world when CZCS was in operation). Days with heavy cloud cover were left unprocessed, as they did not provide any chlorophyll information after atmospheric corrections. The processed data set for the period 1978 and 1986 includes about 110, single day chlorophyll-a maps. These single day images were then used to make monthly and seasonal composites. As there were not enough data to make monthly composites for each year (for example, a monthly composite is available only for October in the year 1984), all data were pooled together and monthly and seasonal composites were made for the whole period. The seasons are defined approximately as follows: first inter-monsoon (March-May), southwest monsoon (June-September), second inter-monsoon (October-November) and northeast monsoon (December-February). Sufficient data were not avail- able to make monthly composites for the period during the southwest monsoon (SW) in part due to heavy cloud cover in the area during this period.

The southwest monsoon produces heavy rains in the southwestern part of the country while the northeast monsoon, which is weaker and shorter-lived than the southwest monsoon, brings rain to the northern and eastern parts of the country. The general pattern of large-scale oceanic currents related to regional oceanic circulation which dominate waters beyond the continental shelf changes seasonally. During the NE monsoon water movements are from east to west and the currents are strongest off the east coast. The NE monsoon drift is rather shallow and exerts little influence on the waters below the thermocline (Wyrtiki 1973). During the southwest monsoon the circulation changes drastically. The currents off south and southwest coast are strongest during the SW monsoon and exhibit a westerly trend. These currents originate from the Arabian Sea and flow from west to east south of Sri Lanka (Wyrtiki 1973; De Bruin et al

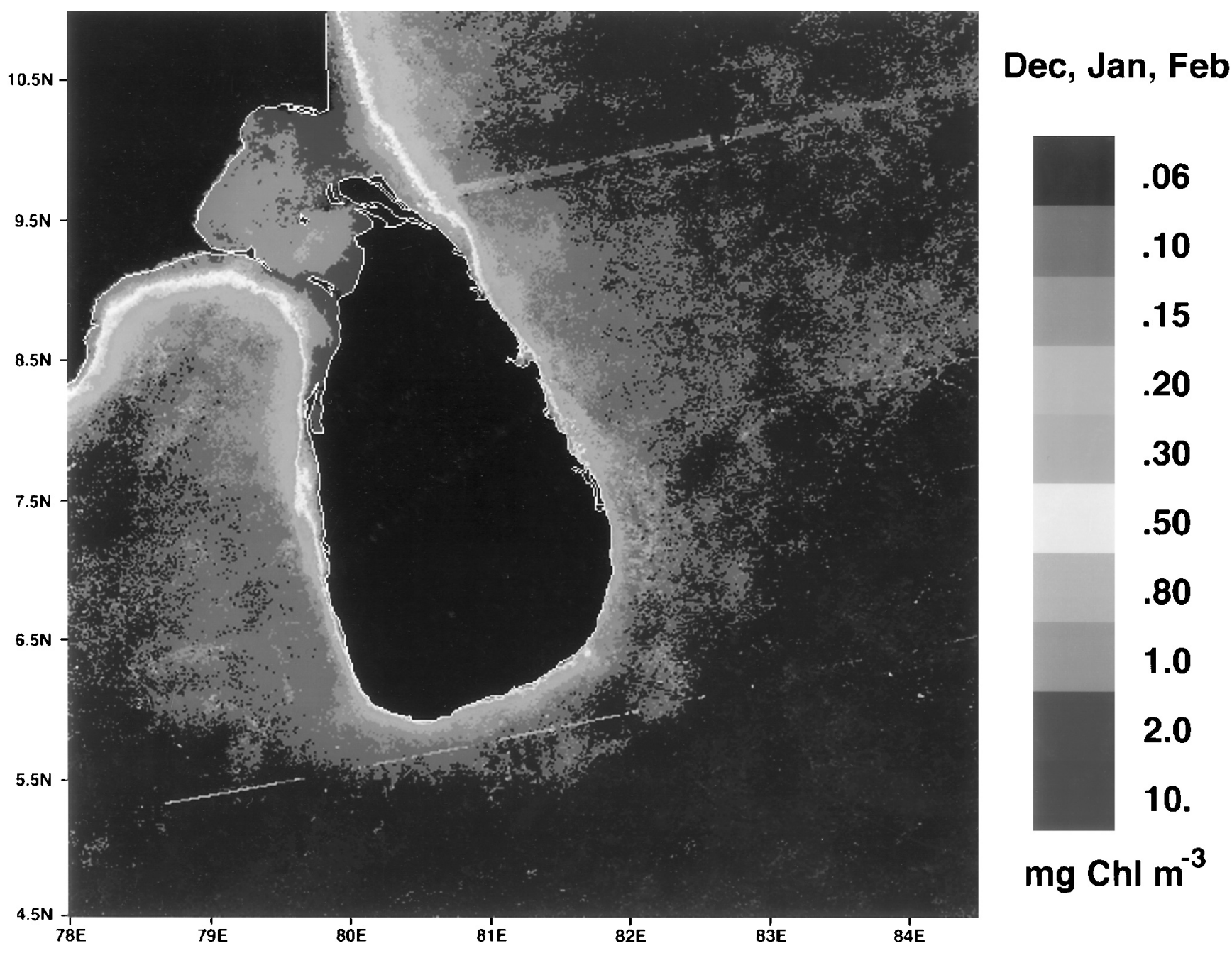

Figure 2. Seasonal composite of surface chlorophyll-a of waters around Sri Lanka for the northeast (NE) monsoon period (December-February). 
1994). The circulation penetrates deeper, affecting the movements of water masses below the thermocline (Wyrtiki 1973).

\section{Results}

Figures 2 and 3 show seasonal composites for the periods, NE monsoon and first inter-monsoon, respectively. Figure 4 shows the composite for the second inter-monsoon period. In all figures land areas are masked with black for clarity. Black patches seen in the water represent no data due to cloud cover. A logarithmic scale is used in the colour code to represent chlorophyll-a concentrations in water. Northern waters within the $100 \mathrm{~m}$ isobath including Gulf of Mannar and Palk Bay (within the area of latitudes $9 \mathrm{~N}-10 \mathrm{~N}$ and longitudes $79 \mathrm{E}-80.5 \mathrm{E}$, approximately), show high chlorophyll concentrations $\left(>0.8 \mathrm{mg} \mathrm{m}^{-3}\right.$ ) throughout the year (figures 2-4) with no apparent variation from month to month. During NE monsoon (figure 2) waters around Sri
Lanka, except in the northern region discussed above, show very low chlorophyll concentrations $(<0.20 \mathrm{mg}$ $\left.\mathrm{m}^{-3}\right)$. There are some coastal areas with higher chlorophyll concentrations (between 0.5 and $2.0 \mathrm{mg}$ $\mathrm{m}^{-3}$ ) visible around the island. During the first intermonsoon period of March-May (figure 3) there are much lower concentrations $\left(<0.10 \mathrm{mg} \mathrm{m}^{-3}\right)$ of chlorophyll-a in waters around Sri Lanka as well except in few coastal areas and in the northern region. It is apparent from figure 4 that higher surface chlorophyll concentrations (between 0.5 and $2.0 \mathrm{mg}$ $\mathrm{m}^{-3}$ ) in a wider surface area in west and southwest oceanic regions (latitudes between $5 \mathrm{~N}$ and $9 \mathrm{~N}$ and longitudes between $78 \mathrm{E}$ and $80 \mathrm{E}$, approximately) during the second inter-monsoon period compared to $\mathrm{NE}$ and first inter-monsoon periods.

\section{Discussion}

The variability of chlorophyll-a concentrations of surface waters around Sri Lanka is presented in this

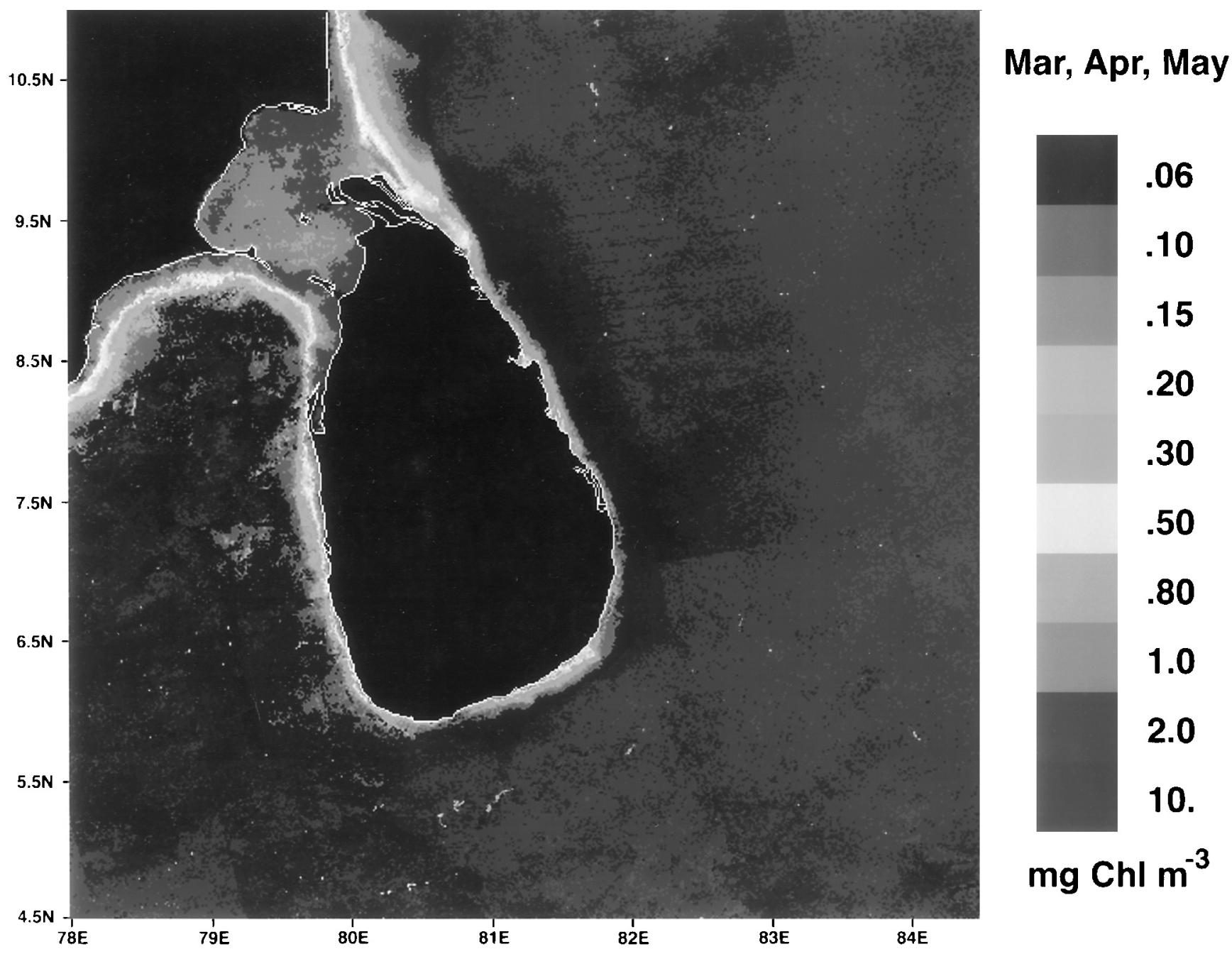

Figure 3. Seasonal composite of surface chlorophyll-a of waters around Sri Lanka for the first inter-monsoon period (March-May). 


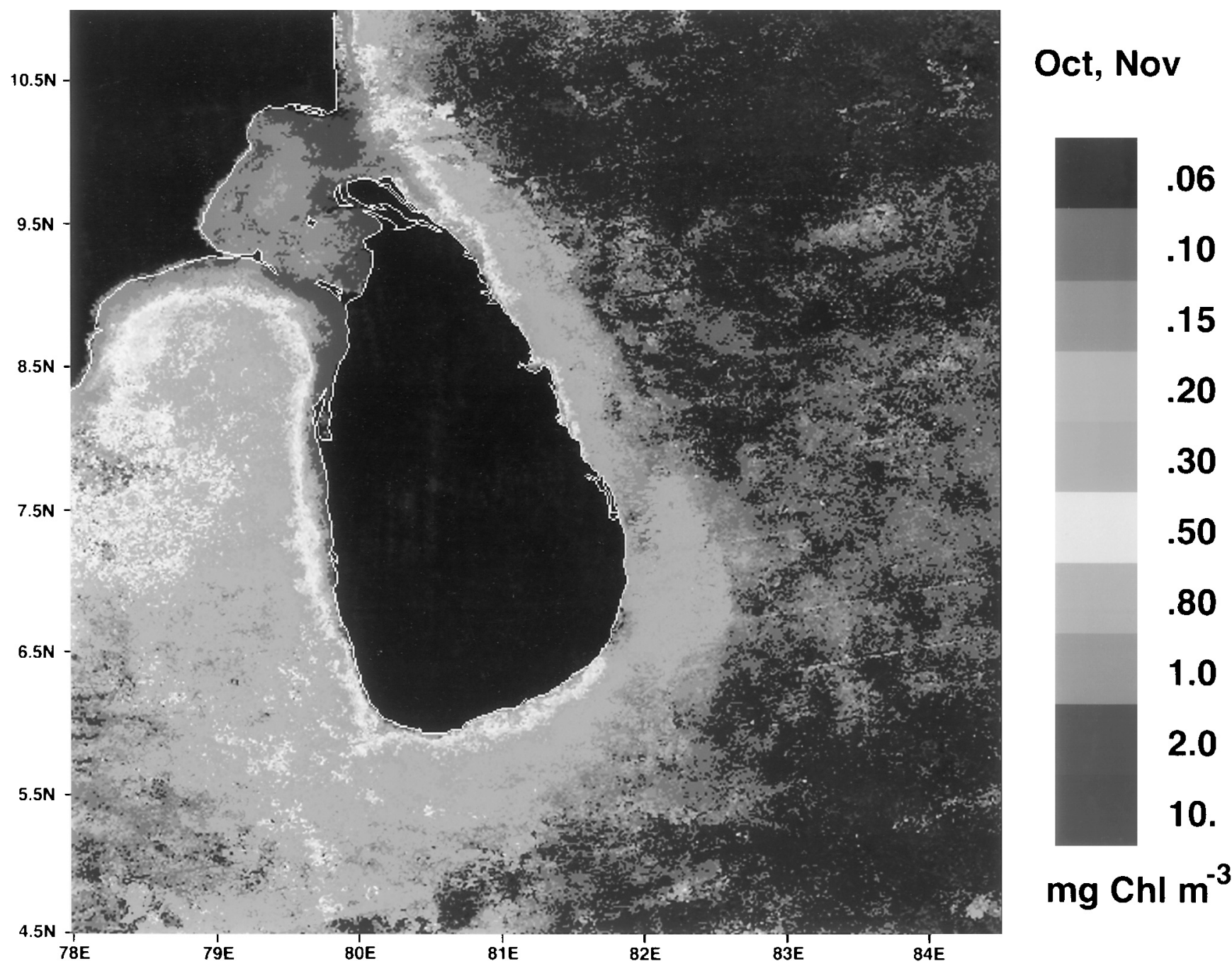

Figure 4. Seasonal composite of surface chlorophyll-a of waters around Sri Lanka for the second inter-monsoon period (OctoberNovember).

study. All three figures indicate that the northern waters (in Gulf of Mannar and Palk Bay areas) have high surface pigment concentrations. The waters in this region is very shallow $(<100 \mathrm{~m})$ when compared to other surrounding waters of the island (figure 1) and therefore these waters may contain other suspended particles and dissolved organic matter in addition to chlorophyll-a. As the algorithm used here is not tuned for case 2 waters and these materials also absorb light at similar wavelengths the derived values for this region may have a higher uncertainty. However, these waters should be sampled for further classification of the particles present. During first inter-monsoon and NE monsoon periods, waters around Sri Lanka except in the north show very low surface pigment concentrations (figures 2 and 3). In general, NE monsoon is considered to be a rather gentle phenomenon, the oceanic circulation is only moderately strong (Wyrtiki 1973) and the surface flow does not penetrate much below the thermocline to bring up cooler waters from deep. Thus, favourable wind conditions may result only in occasional weak upwelling along the coast as can be seen in figure 2 .

It is clear from the images that waters off west and southwest coasts have higher surface pigment concentrations after the SW monsoon. Even though the satellite data were not available sufficiently during SW monsoon, these waters are rich in chlorophyll during this period as well. SW monsoon during JulyAugust is considered to be more vigorous than NE monsoon and found to cause development of a strong western boundary current and also intense upwelling in several areas of the Indian Ocean such as the Arabian Sea. As these waters are deeper and can be considered as open ocean waters, high chlorophyll concentrations seen in this region can be expected due to upwelling rather than due to other particles. During SW monsoon a shallow mixed layer around $30 \mathrm{~m}$ has been found in the region discussed above (Olson 1991) compared to about 50m deep mixed layer during $\mathrm{NE}$ monsoon. As upwelling inhibits deepening of the mixed layer it may suggest possible 
upwelling in the area. The high concentrations of chlorophyll we observe in the western region may be due to after effects of SW monsoon. Persistent upwelling along the West Coast of India has also been observed (Narain et al 1992) in the months of September and October. The surface circulation of the Indian Ocean is from west to east during SW monsoon and probably these currents bring nutrient rich upwelled waters from Arabian Sea and from western Indian Ocean towards west of Sri Lanka, as well. These waters should be further investigated for chlorophyll, temperature, primary productivity and photosynthesis parameters. Waters around Sri Lanka have not been studied extensively for oceanographically important such parameters and we believe that this is a drawback in utilizing available remote sensing data. As high productive areas may indicate possible fishing grounds, these regions need extensive surveys of fish catches during and after SW monsoon. Studies of sea surface temperature data of the waters around Sri Lanka from NOAA satellites are being carried out at present. We expect to analyze LAC data of waters around Sri Lanka from SeaWiFS as well.

\section{Acknowledgement}

Author thanks START secretariat, USA for granting a visiting scientist award for the visit to Bedford Institute of Oceanography (BIO), Canada where processing of images had been carried out. Sincere thanks are due to Dr. Trevor Platt for initiating the visit and providing facilities for the work, and to Linda Payzent and Heidi Bishop for the help given in processing. The author thanks two anonymous referees, especially referee 2 , for constructive comments on the manuscript.

\section{References}

Sathyendranath S and Morel A Y 1983 Light Emerging from the Sea - Interpretation and Uses in Remote Sensing, in Remote sensing application in marine science and technology, (ed) A.P. Cracknell pp 323-357

Gordon H R, Brown O B and Jacobs M M 1975 Computed relationship between the inherent and optical properties of a flat homogeneous ocean; Appl. Opt. 14417

Morel A Y and Prieur L 1977 Analysis of variations in ocean color; Limnol. Oceanogr, 22, 709

Gordon H R and Morel A Y 1983 Remote assessment of ocean color for interpretation of satellite visible imagery (New York: Springer-Verlag) pp 114

Wyrtiki K 1973 Physical Oceanography of the Indian Ocean, in The Biology of the Indian Ocean, (Springer-Verlag) pp 18

De Bruin G H P, Russell B C and Bogusch A 1994 Field guide to the marine fishery resources of Sri Lanka, (FAO) pp 1-8

Olson D B 1991 Mixed layer dynamics in the Arabian Sea, in US JGOFS Planning Group, Report Number 13, pp 49

Narain A, Beena K and Raman M 1992 in Remote sensing applications and geographic information systems: Recenttrends, (ed) I V Muralikrishna (New Delhi: Tata McGraw Hill Publications) pp 332 